\section{Processo de trabalho do agente comunitário de saúde e a reestruturação produtiva}

\author{
Community health agents' work process \\ and restructuring
}

\author{
${ }^{1}$ Departamento de Ciências \\ da Saúde, Universidade \\ Estadual de Santa Cruz, \\ Ilhéus, Brasil. \\ 2 Universidade Federal \\ Fluminense, Niterói, Brasil. \\ 3 Universidade Federal do \\ Rio de Janeiro, Rio de Janeiro, \\ Brasil. \\ Correspondência \\ V. S. C. Ferreira \\ Núcleo de Saúde Coletiva, \\ Departamento de Ciências \\ da Saúde, Universidade \\ Estadual de Santa Cruz. \\ Rodovia Ilhéus-Itabuna Km \\ 16. Campus Soane Nazaré de \\ Andrade, Ilhéus, BA \\ 45662-000, Brasil. \\ vitsoll@gmail.com
}

\section{Abstract}

The current study analyzes the care provided by community health agents in the Family Health Program in Brazil, as characterized by their work process, the techniques they employ, and restructuring of their work. The research adopted a case study design, and data were collected with semi-structured interviews and focus groups. Instruments from the mapping method were used. The results indicate the extensive use of soft and soft-hard technologies in the production of care, backed by work in which the main input was the knowledge acquired by community health agents in the relationship established with target families. Although care centered on live work, in the act, where the community health agents determined their own actions, guided by their subjectivity, their work was subsumed by the logic of the hegemonic model, constituting an on-going dispute in relation to their work process. Despite their care and receptive management, community health agents were unable to "contaminate" the FHP team, shackled by defunct, established, organized work, thus hindering the restructuring process.

Delivery of Health Care; Family Health; Health Technology
Vitória Solange Coelho Ferreira 1

Cristina Setenta Andrade 1

Túlio Batista Franco 2

Emerson Elias Merhy ${ }^{3}$

\section{Introdução}

A primeira experiência de implantação do Programa de Agentes Comunitários de Saúde (PACS) no Brasil, como uma estratégia abrangente de saúde pública estruturada ocorreu, em 1987, no Estado do Ceará 1 e posteriormente foi estendido para todo o Nordeste e Região Norte 2. Em 1992 foi implantado na Bahia e em 1993 na Região Centro Oeste.

A emergência do agente comunitário de saúde (ACS) como trabalhador da saúde faz surgir sentimentos contraditórios. Ele se vangloria de pertencer ao Programa Saúde da Família (PSF): "a formação que recebem lhes dá um sentimento orgulhoso de diferenciarem o seu conhecimento em relação ao conhecimento popular que dispunham previamente, o que lhes confere prestígio social, uma vez que o saber biomédico situa-se numa escala superior na hierarquia de saber da sociedade" 3 (p. 1641). Ao mesmo tempo, verifica-se que no exercício de sua prática cotidiana o ACS tem se revelado um ator instigante no que se refere às relações de trocas estabelecidas entre os saberes populares de saúde e os saberes médicos científicos pela posição que ocupa de mediador entre a comunidade e o pessoal de saúde.

Este estudo pretende analisar o modo de produção do cuidado do ACS de uma equipe de saúde da família, tendo como principais marcadores seu processo de trabalho, as tecnologias de cuidado e a caracterização da reestruturação 
produtiva, como pressuposto para a identificação de que seu trabalho no PSF opera processos de mudança no cuidado às pessoas. Como o trabalho em saúde é dependente do trabalho vivo em ato 4 , buscamos compreender os aspectos relacionados ao sujeito e sua subjetividade, como operadoras da construção do processo produtivo na saúde.

Supomos como pressuposto que o ACS conduz seu processo de trabalho sob as lógicas do "agir tecnológico" e do "agir comunicativo" possibilitando a invenção de novos modos de operar os atos assistenciais, a criação de espaços de fala e escuta qualificada e a construção de vínculos afetivos e efetivos. Assim, ele trabalha sob a tensão de dois pólos: a primeira, centrada na lógica da produção de procedimentos como expressão do cuidado; a segunda privilegia atividades centradas nas necessidades do usuário e prioriza as tecnologias relacionais. Imaginamos que não há um contraditório em si nestas questões, mas elas convivem simultaneamente na realidade, como em uma "dobra", conforme Deleuze (2006, apud Oliveira 5; p. 59): “A dobra mostra um cenário diferente daquele que opunha interior/exterior”.

A micropolítica do processo de trabalho do ACS é atravessada por lógicas próprias das vivências da família no território e domicílio, onde os sujeitos que aí convivem entre si, sofrem afetamentos em seus encontros mútuos, agenciando a produção de diferentes modos e perfis de cuidar. Neste espaço de produção, ocorrem as microconexões, que são instituintes e possibilitam um mergulho em profundidade na cotidianidade do trabalho do ACS 6 .

Quando isso ocorre pelo desejo, enquanto força de constituição do novo dos sujeitos produtores dos atos de saúde, a realidade é entrecortada por um primeiro plano, dos afetos, em que vários fluxos de intensidades se formam no encontro entre trabalhadores, usuários, comunidade e todos os atores implicados com o ato de cuidar. Segundo Deleuze 7 (p. 73): "Daí a força da questão de Espinosa: o que pode um corpo? De que afetos é ele capaz? Os afetos são devires: ora eles nos enfraquecem, quando diminuem nossa potência de agir e decompõem nossas relações (tristeza), ora nos tornam mais fortes, quando aumentam nossa potência e nos fazem entrar em um indivíduo mais vasto ou superior (alegria)".

Segundo Deleuze 7, estes encontros podem produzir "paixões alegres", com aumento de potência e sua força vital, ou "paixões tristes", com a redução da potência e força vital. A produção do cuidado, portanto guarda uma forte conexão com a intenção, as tecnologias relacionais e a liberdade do próprio ACS na operação do seu processo de trabalho.
Essas relações operam como fluxos que se interpenetram e entrecruzam em várias direções de forma rizomática, não só entre a equipe, desta com os usuários, como também com outras equipes e serviços, produzindo uma rede capaz de disparar processos de desterritorialização e reterritorialização produtor de devires 8,9.

Ademais, podem também agenciar outras conexões e fluxos não produtores de devires e de vida, mas de reprodução e de morte como todos os tipos de violência, de segregação, de dominação, de mistificação, de ditaduras através dos processos de semiotização.

Um segundo plano, organizacional ocorre o encontro entre os diversos agentes institucionais portadores de diferentes projetos e interesses que se relacionam, disputam e produzem contratualidades conforme as relações de micropoderes 10 e os tipos de poder presentes nas estruturas dessas organizações, a saber: o político, o técnico e o administrativo 11 .

De um lado, o trabalho em saúde tende a ser compreendido no nível das representações sociais dominantes como profundamente ancorado na ciência assumindo seus instrumentos de trabalho materiais uma posição privilegiada, de outro, assume as particularidades inerentes à divisão social e técnica do trabalho 12,13, que organiza os serviços de saúde para produção do cuidado a partir de duas lógicas, a saber: a do trabalho artesanal do tipo profissional, e a do trabalho parcelado, em que a concepção e execução se dão separadamente alienando o trabalhador do processo de produção global 14,15.

A organização tecnológica do processo de trabalho tem se constituído em um forte analisador 16 da organização da assistência à saúde, por revelar a paradoxal relação entre o trabalho morto e trabalho vivo no núcleo produtivo do cuidado. Em situações de forte captura do trabalho vivo, na ação cotidiana dos trabalhadores, e mesmo nas tensões específicas do processo produtivo, abrem-se "linhas de fuga", formas singulares de cuidar são exercidas, sendo o trabalho vivo, que opera em alto grau de liberdade, o propulsor destas linhas.

Para Merhy 17,18 o trabalho em saúde é um processo relacional, produzido através do trabalho vivo em ato, ou seja, a partir do encontro entre duas pessoas onde se estabelece um jogo de expectativas e produções criando espaços de escutas, falas, empatias e interpretações. Utiliza para sua realização as tecnologias de saúde tipificadas como: (a) tecnologias duras têm em sua estrutura uma característica dada a priori; (b) leve-duras apresentam uma parte estruturada, o conhecimento, e outra leve relacionada ao modo de agir singular de cada trabalhador; 
e (c) leves dizem respeito aos aspectos inter-relacionais.

A reestruturação produtiva ocorre pela introdução de inovações na organização do processo produtivo, seja pela incorporação de novas tecnologias duras (maquinaria), seja pela mudança no modo de operar o processo de trabalho. Pode gerar também mudanças no modo de elaborar os atos em saúde, e na forma de cuidar, mas ela não necessariamente altera o núcleo tecnológico da produção do cuidado, isto é, pode ocorrer mesmo sob o modelo hegemônico. Por exemplo: a incorporação de novas tecnologias (máquinas) em um hospital, ou a implantação do PSF em uma rede de atenção básica, não significa necessariamente alteração do modo de produção, pois isto pode se dar ainda dentro do processo produtivo centrado na produção de procedimentos 19

Assim, a mudança do modelo produtivo requer o reordenamento do núcleo tecnológico do cuidado, com primazia do trabalho vivo sobre o trabalho morto, expressão da liberdade; relevância nas tecnologias leves e leve-duras, sobre as duras que devem ficar na posição acessória às demais, o que significa uma aposta nas relações como modus operandi por excelência do processo de trabalho; e a constituição de processos auto-analíticos e autogestionários na equipe de trabalhadores, que favoreçam a elaboração de intervenções na micropolítica do processo de trabalho, possibilitando a superação das situações de repetição dos modelos vigentes, resignificando seus atos assistenciais.

\section{Trajetória metodológica}

Este trabalho se insere no campo da investigação qualitativa. Trata-se de um estudo de caso em que se pretende verificar as singularidades da realidade, do vivido, nos quais estão em produção trabalhadores e usuários com seus sentidos, significados, sonhos, desejos, crenças, valores e atitudes em constante processo de singularização e também de serializações. Foi no sentido de capturar as inter-subjetividades presentes nos movimentos que foram sendo traçados pelo ACS no cotidiano do seu processo de trabalho, que se utilizaram instrumentos do método cartográfico, por reconhecer a realidade como um mapa em aberto que se processa em redes rizomáticas, a partir dos fluxos-conectivos que operam entre os sujeitos na micropolítica do trabalho em saúde 20,21. A escolha dessa estratégia justifica-se por buscar na leitura do processo de trabalho, a produção de sentido, as relações inter-subjetivas, os afetos, no cotidiano de produção do cuidado.
A compreensão do que é a cartografia sugere ao pesquisador dar "língua aos afetos", pois é através deles que se processam as conexões e os fluxos de intensidades conformadores de novas subjetividades, capazes de fazer com que os sujeitos produzam determinadas formas de agir sobre a realidade, configurando-a conforme seus próprios sentidos. Segundo Kastrup 22 (p. 7), “ $a$ cartografia não é um método que vise apresentar uma análise exaustiva ou totalizante, mas busca circunscrever um plano coletivo de sentido, sistemas de signos que não desenham uma identidade, mas ao contrário, permitem detectar os elementos de processualidade do território em questão". É isto que se pretende, buscar os territórios sobre os quais o ACS transita ao produzir o cuidado, revelar seu processo de trabalho, dentro dos sentidos que lhe dá, e com base nas vivências cotidianas, nos encontros e por conseqüência, a produção de si mesmo como sujeito do trabalho em saúde.

Toma-se emprestado da esquizoanálise, algumas concepções por considerá-la como uma nova forma de pensar, de ser e de viver não possuindo, portanto, técnica nem metodologia própria. Ademais, os princípios teóricos que a norteiam propiciam por si a invenção de estratégias singulares para cada caso ou situação permitindo a compreensão dos aspectos da realidade.

Foram utilizados os seguintes marcadores para analisar os dados obtidos da pesquisa: (a) as tecnologias de trabalho, citadas neste texto - duras, leve-duras e leves; (b) o grau de liberdade de ação do trabalho vivo em ato, verificado através da capacidade inventiva do ACS no seu cotidiano de trabalho, as conexões e fluxos que o agente é capaz de operar, formando redes de cuidado; (c) a capacidade de captura do modelo hegemônico sobre o trabalho do ACS, que pode se revelar na sua intenção em realizar procedimentos, sobrepondo-se à sua atividade mais vinculada ao campo cuidador, da educação em saúde e ao uso das tecnologias mais relacionais; (d) os afetos provocados pelos encontros do ACS com os outros sujeitos do cuidado, isto é, sua capacidade de afetar e ser afetado na atividade cotidiana de cuidado; (e) relações de poder na equipe de Saúde da Família, que revelam a porosidade da equipe para participação efetiva do ACS nas discussões e decisões, especialmente as relacionadas aos projetos terapêuticos; e (f) os processos de desterritorialização e/ou reterritorialização no cenário em que se configura o trabalho do ACS, que é em síntese o processo que se busca de análise de supostos deslocamentos verificados no seu processo de trabalho, que revelam uma reestruturação produtiva, com a realização de novos sentidos para o cuidado em saúde. 
O Município de Itabuna, onde foi realizado o estudo, localiza-se na região Litoral Sul do Estado da Bahia, a $429 \mathrm{~km}$ da capital, com $584 \mathrm{~km}^{2}$, população estimada em 210.604 habitantes, integra a 7 a região administrativa. O Sistema Municipal de Saúde apresenta organização modular, possui uma rede de serviços composta por 9 unidades básicas de saúde, 18 unidades de saúde da família, 10 unidades especializadas, e 24 serviços de apoio diagnóstico e terapêutico e 6 hospitais, sendo um público, com 220 leitos, dois filantrópicos e três privados e conveniados ao SUS, com 806 leitos. O PACS foi implantado em 1992, atualmente cobre $55,6 \%$ da população com 310 ACS e 24.436 famílias cadastradas. O PSF foi implantado em 2001 e atualmente conta com 18 equipes de saúde da família (Secretaria Municipal de Saúde de Itabuna; http://www.saudeitabuna.com.br/).

Foi escolhida como campo de estudo uma unidade saúde da família, composta por médico, enfermeira, seis ACS, uma recepcionista, um auxiliar de enfermagem e um técnico de enfermagem, um nutricionista, um odontológo, uma recepcionista, um agente administrativo e uma auxiliar de serviços gerais, e como os sujeitos da pesquisa, seis ACS. O processo de escolha da unidade envolveu os seguintes critérios, a saber: (a) ter mais de dois anos de implantação; (b) possuir uma equipe mínima trabalhando; (c) sensibilização da equipe da saúde da família para com a pesquisa; (d) estrutura física mínima para funcionar; e (e) ter grupo de gestante em atividade. Teve como instrumentos de coleta de dados a observação direta realizada pontualmente, durante uma semana, acompanhado os ACS no território e domicílio, a entrevista semi-estruturada e o grupo focal realizado em duas sessões, com gravação em audio e vídeo, cada uma com 50 minutos. A análise foi feita através da leitura minuciosa e repetida das entrevistas, bem como a observação sistemática sobre o áudio e vídeo do grupo focal, retirando deste material o conteúdo que dá significado à micropolítica do processo de trabalho do ACS. Não seguiu um plano traçado a priori por entender que muitos dos procedimentos utilizados teriam que ser inventados em função daquilo que pede o contexto no qual esta inserido, ou seja, de acordo com as mudanças que iam sendo desenhadas pelo ACS no seu cotidiano de trabalho. Assim, à medida que eram identificados os traçados pelos quais se desenhava a produção do cuidado pelo ACS, foi se processando a análise.

Vale destacar que a pesquisa foi aprovada pelo Comite de Ética e Pesquisa do Hospital Universitário Clementino Fraga Filho, Faculdade de Medicina, Universidade Federal do Rio de Janeiro (UFRJ) e assinado o Termo de Consentimento Li- vre e Esclarecido pelos sujeitos partícipes do estudo, os quais receberam nomes fictícios.

\section{Resultados e discussão}

Cartografar o material empírico coletado possibilitou "mergulhar" na cotidianidade da micropolítica do processo de trabalho do ACS onde se verificou preliminarmente uma permanente disputa e tensão entre o agir de seu trabalho vivo, que opera entre um trabalho centrado nas tecnologias leves e leve-duras, e outro mais normativo, aprisionado pela lógica instrumental do trabalho morto no qual opera com supremacia o modelo biologicista de intervenção e o sanitarista burocrático referenciado pelas tecnologias duras.

Essa conformação ganha contornos mais nítidos à proporção que se observava a implicação do ACS com a produção de um cuidado-cuidador no território e domicílio, expressos pela capacidade de reconhecer a singularidade de cada família e desenvolver estratégias diferenciadas de cuidado, atendendo à singularidade dos usuários e seus problemas de saúde. Exemplos notórios são citados pelos ACS em relação à administração de medicamentos a pessoas analfabetas ou cegas, quando inventam instrumentos que facilitam o auto-cuidado destas pessoas e sua autonomia; ao manejo de crianças para pesagem, quando utilizam de referenciais simbólicos do mundo infantil para facilitar a adesão das crianças a este procedimento, como pode ser visto no fragmento de fala do grupo focal: “...tive que pegar as bonecas delas e brincar, ... quer dizer, pesei as bonequinhas delas, foi aí que ela se interessou e quando me via você vai pesar hoje" (ACS Pérola).

Outro aspecto a considerar é a horizontalização das relações de poder que parece ocorrer no momento em que o ACS e os profissionais da equipe se encontram no trabalho, em ambiente domiciliar. A singularidade desse encontro, a inter-subjetividade presente, possibilita a composição de afetos entre ACS, médico e enfermeira, usuário e família, amplia os espaços de compartilhamento da gestão do cuidado pela equipe.

O ACS infere que organiza seu processo de trabalho no domicílio segundo um certo "cronograma”, que copia um modo já tradicional de organização do processo de trabalho na rede de saúde, centrado nas ações programáticas, que classifica as nosologias mais comuns presentes na área e indica os dias em que serão atendidos os usuários portadores destes agravos.

Esse modo de operar a assistência faz com que os trabalhadores e em especial o ACS sofram uma captura por parte de um suposto "protocolo" de visitas, quando diz que em determina- 
das semanas visita "só hipertenso", na outra "só criança”, e na seguinte apenas gestante etc. Nesse caso, observa-se que o processo de trabalho do ACS no domicílio está sendo comandado mais pelo recorte programático do que pelo critério da necessidade.

Além dessa lógica programática de visitação, outras inovações vão sendo instituídas, como o recorte organizacional de seu trabalho na micro-área de atuação por rua, buscando atender integralmente a família no domicílio, com exceção para o peso da criança que continuava sendo agendado. No grupo focal, os ACS informam que fazem atendimento também por demanda espontânea no território, isto é, fazem visitas e cuidado que não haviam sido programados previamente, pois eles são demandados por moradores quando transitam entre as residências. Assim, abrem linhas de fuga do suposto "atendimento programado" para centrar seu trabalho nas necessidades do usuário. Na observação direta foi possível acompanhar essa forma de atendimento.

“...Nem sempre a rotina que você faz você termina, porque é assim, você tá em uma rua aí quando pensa que não chega um: 'ah, aquele senhor mandou te chamar porque tá passando mal!' ... 'ah, aquele senhor ali falou que quer um exame!'. Aí você tem que largar aquela família, terminar aquela visita dele 'ah, peraí ainda que eu já vou' ai você já vai pra outra rua" (ACS Jade).

Observa-se que o trabalho do ACS é, por um lado, subsumido pelas lógicas do modelo hegemônico estruturado sobre os núcleos especializados de saber profissional; e por outro lado assume formas inventivas e criativas de cuidar no contexto do modelo tradicional de produzir saúde, conseguindo em momentos pontuais transitar deste para outro modelo, em movimentos em dobra, trabalhando às vezes de um jeito e outras vezes de outros diferentes, não em contradição, mas em singulares modos de agir, em identidades com um ou outro modelo.

Fazer parte do mesmo universo sócio-cultural e lingüístico da comunidade tem possibilitado a composição de bons encontros entre o ACS e os usuários, que tendem a aumentar a sua "potência de agir", e se expressa positivamente no modo de cuidar. As relações, experiências e vivências que foram sendo construídas no cotidiano de sua vida e trabalho criam laços afetivos de solidariedade, de compromisso, de responsabilidade, de confiança, de cumplicidade entre as famílias e o ACS que vão contribuir com a formação de uma subjetividade solidária, e a instituição de uma nova ética no modo de fazer saúde.

A equipe de saúde da família desqualifica a ação cuidadora do ACS, não reconhecendo ne- le a competência para a construção de um tipo de cuidado diferente daquele centrado na lógica programática, e constrange-o à repetição do atual modelo. $\mathrm{O}$ agente de saúde por sua vez, procura trabalhar com ações de promoção para legitimar o seu trabalho. Entre os recursos que utiliza estão os prospectos educativos produzidos por outras redes de cuidado, ligadas às clinicas privadas, como forma de ter "uma orientação mais apurada" e atender as demandas das famílias e dos indivíduos orientando como, por exemplo, sobre o "climatério".

O jogo de disputa na equipe de saúde da família é expressão dos micropoderes que permeiam as relações de trabalho, ligados sobretudo à hierarquização do saber que se coloca entre os ACS, a equipe legitimada pelos níveis de gestão da secretaria de saúde. Essas relações inter-equipe se referem à divisão técnica do trabalho em primeira instância, e também à divisão social, que fragmenta, aliena, subordina a produção do trabalhador manual ao do trabalhador intelectual restringindo a sua participação nos processos decisórios. É como se, no imaginário dos outros profissionais da equipe, o ACS representasse o lugar do trabalhador manual, aquele que não detém um núcleo especializado de saber, e um núcleo profissional específico. E por isto mesmo os outros trabalhadores o colocam em um plano em que o seu trabalho tem menor valorização em relação aos outros. Os ACS entrevistados referem que eles são vistos pelos outros trabalhadores e pela gestão, mais como um "trabalhador manual”, como se não detivessem um campo de saber e capacidade cognitiva de operar com o cuidado em saúde.

“...Dentro da própria unidade acontece isso, montarem os projetos, palestras e cursos, deixam as coisas assim mais dificeis, mais pesadas, sobrarem para os agentes comunitários, ...se for fazer lanche, se for fazer panfleto, se for tirar xérox, se for fazer cartaz, se for fazer uma faixa os agentes comunitários que tem que ir arregaçar as mangas e procurar fazer..." (ACS Jade).

Outro aspecto a ser considerado, refere-se ao modelo de organização da gestão do cuidado, e à organização do trabalho que se estrutura por relações hierarquizadas. No caso dos ACS, todos esses aspectos tendem a capturar o seu processo de trabalho, ampliando e reproduzindo um modo de produção do cuidado centrado em procedimentos. Observa-se que o saber técnico subsume outros saberes que eventualmente se manifestam como o saber-cuidador, centrado em tecnologias mais relacionais e mantém a equipe pouco permeável a inovações no processo de trabalho do ACS. Seu trabalho vivo é capturado em ato. 
Nos discursos presentes, no grupo focal e nas entrevistas individuais, foi observado que a existência de poucos espaços de escuta e diálogo na equipe não tem permitido a participação do ACS nos processos decisórios relacionados à gestão do cuidado, a organização e funcionamento dos serviços de saúde, como pode ser visto nas falas do ACS quando diz em entrevista grupal que " $o$ apito do agente é surdo"; ou quando referem que levam necessidades das famílias as quais acompanham, e sua opinião não é considerada pela equipe na elaboração das estratégias de cuidado formuladas em reunião. A relação inter-subjetiva, que se dá por via da fala entre o ACS e a equipe é pontual, destina-se à troca ou à transmissão de informação técnica, visando atender às demandas imediatas dos usuários.

“...Na equipe acho que tá sendo um pouco diferente... falar é muito bonito que o profissional do PSF depende do agente comunitário, mais na realidade quando vai ver o agente comunitário éo último como dizer assim" (ACS Turquesa).

“...Às vezes nem tá olhando a necessidade da família tem umas com a necessidade maior e não tá indo naquela família e sim na outra, aí não tá havendo essa" (ACS Pérola).

A inexistência de espaço de elaboração coletiva de planejamento do trabalho, avaliação do cuidado e de critérios de priorização das famílias que necessitam de visitas, faz com que os ACS criem estratégias de "gestão colegiada" do seu processo de trabalho, para discutirem e resolverem os problemas verificados nas diversas micro-áreas. Como por exemplo: eles operam entre si, uma micro-rede solidária para garantir o agendamento para o usuário que está mais grave, mais necessitado, situação em que um ACS repassa a outro sua "vaga" ou "ficha" para consulta, entendendo que o usuário sob cuidados do colega estaria mais necessitado.

No entanto, ressalta-se que a produção da subjetividade é processual, não está dada a priori e no agir cotidiano de sua prática, o ACS pode operar entre si diferentes modos de fazer, uma vez que afeta e sofre afetamentos, atravessa e ao mesmo tempo é atravessado por diferentes lógicas agenciadoras de micro-redes de todos os tipos e matizes: capitalística e humanitária, a solidária e a fascista, a clientelista e a de "pendor para ajuda solidária” entre outros.

Os saberes e práticas que informam o modo de agir dos ACS reproduzem, e muitas vezes ampliam, o modelo hegemônico, ao utilizar centralmente no desenvolvimento de suas atividades os saberes que se referem ao núcleo específico das profissões de saúde, mesmo que tenham como instrumento de atuação a educação sanitária. As ações e práticas educativas que os desenvolvem têm como eixo as práticas de promoção e proteção à saúde, voltadas para a história natural das doenças, quando referem: “... a importância dos exames, o porquê da importância do pré-natal na vida da mãe e do bebê, aí eu falo também da importância da sífilis e da rubéola, hepatite aí cada mês eu falo sobre a importância de uma doença..." (ACS Jade).

“...O agente de saúde chegar e conversar falar sobre higiene, sobre os perigos de andar descalço, os cuidados para quem anda descalço, sobre verminose, essas coisas; pronto sobre higiene" (ACS Safira).

Não reconhecem que o cuidado e seus resultados são uma produção humana, em que aspectos do processo de trabalho e do modo de produzir se estruturam como algo criado pelos próprios sujeitos trabalhadores.

Esse modo de atuação pode ser evidenciado nas falas dos ACS acerca do trabalho em saúde e a relação que fazem deste com a educação. Essa compreensão encontra-se arraigada no campo de produção subjetiva do ACS, fortalecendo a crença de que as ações educativas per se, teriam potência para modelar comportamentos, valores e visões de mundo, melhorando a qualidade de vida e autonomizando os sujeitos em seu modo de andar a vida.

Este tipo de análise está muito presente nos serviços de saúde, como demonstra a citação de Gonçalves 23 (p. 113) de que “...era preciso que se restabelecessem os nexos entre as características do hospedeiro e o desenvolvimento da doença, capazes de sustentar a concepção de que através do comportamento modificado se pudesse obter o controle das mesmas" e o discurso dos entrevistados quando referem "...é uma total assim falta de higiene se eles tivessem assim um princípio de educação não estariam assim".

Observa-se também nessas falas que as práticas educativas desenvolvidas para ensinar a comunidade o auto cuidado e a adoção de estilos de vida saudáveis têm produzido uma normatização na vida das pessoas que tem muitas vezes gerado conflitos e resistências na aceitação de tais orientações. Sabe-se que o ato de fala por si não implica necessariamente mudanças no modo de os sujeitos envolvidos andarem a vida 24 . Por outro lado, a desqualificação do patrimônio de conhecimento da população, produzido pelo saber científico, produz apatia e pouca participação da comunidade na gestão da unidade, do cuidado e nos grupos educativos ou de apoio. 


\section{Considerações finais}

O processo de trabalho em saúde e suas tecnologias têm se constituído em um analisador potente da gestão do cuidado, e do trabalho nos serviços de saúde, por possibilitarem a identificação de ruídos, potencialidades, limites, presentes na malha progressiva de cuidado à saúde. A análise que se segue, tem por base os marcadores definidos para este estudo, que se encontram relacionados como sub-itens apenas para demonstração didática, mas estão todos eles em interseção, ou em dobra, onde os limites entre si ficam indefinidos.

\section{As tecnologias de trabalho}

Em se tratando da organização do processo de trabalho do ACS, observa-se a presença de duas lógicas conflitantes no desenvolvimento de sua prática. A primeira representada por um conjunto de técnicas, normas e procedimentos ou na medicalização da doença, encontra-se sustentada pela racionalidade normativa e instrumental e pode ser visualizada através das ações de educação à saúde de cunho informativo, corretivo e prescritivo das práticas de higiene e do auto cuidado dirigidas às famílias. Em muitos momentos, prevalece esta lógica de trabalho, centrada nas tecnologias duras. Por outro lado, em outra face da "dobra" aparece o ACS com alto grau de liberdade no seu trabalho, operando sobretudo as tecnologias mais relacionais. Esse suposto contraditório demarca sua rotina de trabalho, sendo que o ACS se encontra no centro de tensão entre as duas lógicas.

\section{O grau de liberdade de ação do trabalho vivo em ato}

Como se trata de um processo em construção que se encontra em diversas fases e com graus variados de implementação, duas possibilidades podem ser levantadas, uma estaria relacionada à total captura do processo de trabalho do ACS para dentro do núcleo duro do modelo de intervenção hegemônico. A outra possibilidade seria de que a transversalidade que comanda os bons encontros, com os diversos corpos presentes no seu cotidiano de trabalho, fosse capaz de ampliar o grau de liberdade do seu trabalho vivo em ato e sua capacidade inventiva e criadora na elaboração dos atos assistenciais, mesmo que o faça em permanente tensão.

Apesar de desenvolver uma ação cuidadora, o ACS sofre um processo de captura do saber nuclear das profissões de saúde e instituições correlatas, ficando o seu trabalho marcado por uma permanente tensão e disputa. De um lado, temos o trabalho vivo centrado nas tecnologias leves e relacionais, de outro, o trabalho morto centrado na lógica instrumental e onde operam os modelos biologicistas, programáticos e suas formas de captura.

\section{Os afetos provocados pelos encontros do ACS com os outros sujeitos do cuidado}

A outra racionalidade situa-se no território das relações, das afecções, dos desejos, das implicações colocando-se sempre em uma dobra, possibilita o agenciamento de dispositivos que tende à busca de inovações no modo de gerir o cuidado, coloca o usuário no centro da atenção e da gestão. Encontra-se centrada nos bons encontros que o ACS estabelece com as famílias e são expressos através de suas ações cuidadoras ao demonstrar carinho, preocupação e compreensão com o sofrimento e necessidade do outro, desenvolver e inventar estratégias diferenciadas de cuidado e reconhecer singularidade de cada caso. O outro lado da dobra revela as tensões com a equipe, o não reconhecimento da sua capacidade técnica de trabalho, a captura do seu processo produtivo e sua forma de fuga deste cenário, busca legitimidade em produção da rede privada de cuidado à saúde. O contraditório vai revelando o mundo complexo de atuação do ACS no seu cotidiano.

Reestruturação produtiva; desterritorialização/ reterritorialização do processo de trabalho do ACS

Em relação ao processo de reestruturação produtiva, apreende-se que o ACS vive uma tensão e conflito que são constitutivos do seu processo de trabalho, pelas disputas permanentes que ocorrem entre os campos de força presentes em seu cotidiano. O primeiro é comandado pela lógica cuidadora e criatividade do ACS na elaboração de novos projetos terapêuticos, que são estimuladas pela sua ação no território e domicílio e no contato com os usuários. O segundo tem como representante a racionalidade instrumental, normatizada e estruturada por um saber técnico, representado pelo modelo programático e o cronograma que capturam o seu processo de trabalho.

Apesar de não possuir um núcleo especializado de conhecimento, o ACS utiliza a dimensão cuidadora do seu processo de trabalho para produzir um cuidado centrado no usuário. Torna claro que uma intencionalidade o move nessa direção, para um processo de trabalho mais relacional, tanto com o usuário quanto com os outros ACS, constituindo redes solidárias entre si. Sua subjetividade opera nesta "vontade de cuidar", 
expressão do seu desejo que atua como propulsor da construção social do seu trabalho.

Por outro lado, observou-se que o ACS não tem potência suficiente para contaminar o processo de trabalho da equipe, por estar fortemente implicado com o território instituído das práticas hegemônicas do cuidado, que se legitima a existência dos trabalhadores de saúde. Essa relação de identificação o aprisiona neste território existencial, sofrendo a ação de captura do modelo dominante que é o programático, fortemente burocratizado no cronograma. Tais processos ocorrem não porque seja apenas vítima mas também, porque é protagonista contribuindo com sua ampliação e reprodução. Seu saber-fazer continua em certa medida estruturado pelas normas, protocolos e ações de prevenção e promoção prescritas, voltadas para doença.

Este território normativo, capturante das potências criativas, figura como a superfície de registro-controle, que comanda os processos de cuidado do modelo hegemônico. No entanto, na liberdade do seu "trabalho vivo" o ACS faz ranhuras nessa superfície, operando ao mesmo tempo em lógicas por ele mesmo inventadas, de cuidados à saúde. Este é o movimento contínuo de territorialização e desterritorialização, expressão real, que vai caracterizar a singularidade da micropolítica do seu processo de trabalho.

\section{Resumo}

O presente estudo analisa a produção do cuidado pelo agente comunitário de saúde (ACS) na Saúde da Família, tendo como marcadores seu processo de trabalho, as tecnologias de cuidado e a caracterização da reestruturação produtiva. Teve como estratégia de pesquisa o estudo de caso e como fonte de coleta de dados a entrevista semi-estruturada e o grupo focal. Foram utilizados instrumentos do método cartográfico. Os resultados apontam para utilização extensiva de tecnologias leves e leve-duras na produção do cuidado, sustentada por um trabalho que teve como principal insumo o conhecimento adquirido pelo ACS na relação que estabelece com a família. Apesar de realizar um
Estudo realizado sobre a produção do cuidado na rede básica de atenção à saúde 25 nos informa que os saberes e práticas hegemônicos ainda dominam o processo de trabalho da equipe, contudo poucos são os profissionais que conseguem subverter essa lógica para criar linhas de fuga e produzir um cuidado mais relacional e acolhedor. Observou-se, nesses casos, que o processo de captura do seu agir cotidiano pela lógica flexneriana está fortemente territorializado e instituído.

Por tudo o que foi relatado, podemos concluir que o trabalho do ACS não é suficiente para produzir um processo de reestruturação produtiva no PSF. Ele se desterritorializa do modelo centrado em procedimentos, quando opera um processo de trabalho com base nas tecnologias relacionais, usa da liberdade do seu trabalho vivo em ato para inventar e criar formas de cuidado eficazes, singulares. Mas estes processos não têm potência suficiente para produzir na equipe de saúde da família um processo de mudanças, caracterizando a construção de um novo território ético-político-existencial de ação no processo de produção do cuidado. A equipe permanece territorializada no modelo anterior, deslegitima e questiona a ação do ACS naquilo que ele inova. cuidado centrado no trabalho vivo em ato, governando ele mesmo suas ações e guiado por sua subjetividade, seu trabalho é subsumido pela lógica do modelo hegemônico, configurando uma permanente disputa em relação ao seu processo de trabalho. No que pese sua prática cuidadora e seu manejo acolhedor, não consegue contaminar a equipe que se encontra aprisionada pelo trabalho morto, instituído e organizado, dificultando o processo de reestruturação produtiva.

Assistência à Saúde; Saúde da Família; Tecnologia em Saúde 


\section{Colaboradores}

V. S. C. Ferreira redigiu o artigo. T. B. Franco orientou a redação, revisou e redigiu o artigo. E. E. Merhy orientou a redação e revisou o artigo. C. S. Andrade revisou a redação e participou da coleta e análise dos dados.

\section{Referências}

1. Tomaz JBC. O agente comunitário de saúde não deve ser um "super herói”. Interface Comun Saúde Educ 2002; 6:75-94.

2. Fundação Nacional de Saúde. O Programa de Agentes Comunitários de Saúde (PACS). Brasília: Ministério da Saúde; 1994.

3. Nunes MO, Trad LB, Almeida BA, Homem CR, Melo MCIC. O agente comunitário de saúde: construção da identidade desse personagem híbrido e polifônico. Cad Saúde Pública 2002; 18:1639-46.

4. Merhy EE. Saúde: a cartografia do trabalho vivo. São Paulo: Editora Hucitec; 2002.

5. Oliveira RM. Tecnologia e subjetivação: a questão da agência. Psicol Soc 2005; 17:56-60.

6. Baremblitt G. Compêndio de análise institucional e outras correntes: teoria e prática. Rio de Janeiro: Editora Rosa dos Tempos; 2002.

7. Deleuze G, Parnet C. Diálogos. São Paulo: Escuta; 1998.

8. Deleuze G, Guattari F. O anti-Édipo: capitalismo e esquizofrenia. Lisboa: Assírio \& Alvim; 1972.

9. Guattari F, Rolnik S. Micropolítica: cartografias do desejo. 7a Ed. Petrópolis: Editora Vozes; 2005.

10. Foucault M. Microfísica do poder. Rio de Janeiro: Graal; 2006.

11. Testa M. Pensar em saúde. Porto Alegre: Artes Médicas; 1992

12. Braverman H. Trabalho e capital monopolista: a degradação do trabalho no século XX. 3a Ed. Rio de Janeiro: Zahar Editores; 1981.

13. Marx K. O capital: crítica da economia política. l. 1, v. 1. 23a Ed. Rio de Janeiro: Editora Civilização Brasileira; 2006.

14. Pires D. A estrutura objetiva do trabalho em saúde. In: Leopardi MT, organizador. O processo de trabalho em saúde: organização e subjetividade. Florianópolis: Editora Papa-Livros; 1999. p. 25-48.

15. Ribeiro EM, Pires D, Blank VLG. A teorização sobre processo de trabalho em saúde como instrumental para análise do trabalho no Programa Saúde da Família. Cad Saúde Pública 2004; 20:438-46.
16. Lourau R. A análise institucional. Petrópolis: Editora Vozes; 1975.

17. Merhy EE. Em busca do tempo perdido: a micropolítica do trabalho vivo em saúde. In: Merhy EE, Onocko R, organizadores. Agir em saúde: um desafio para o público. São Paulo: Editora Hucitec; 1997. p. 71-112.

18. Merhy EE. A perda da dimensão cuidadora na produção da saúde: uma discussão do modelo assistencial e da intervenção no seu modo de trabalhar a assistência. In: Campos CR, Malta DC, Reis AT, Santos AF, Merhy EE, organizadores. Sistema Único de Saúde em Belo Horizonte: reescrevendo o público. São Paulo: Xamã; 1998. p. 103-42.

19. Franco TB. Processos de trabalho e transição tecnológica na saúde: um olhar a partir do sistema cartão nacional de saúde [Tese de Doutorado]. Campinas: Faculdade de Ciências Médicas, Universidade Estadual de Campinas; 2003.

20. Deleuze G, Guattari F. Mil Platôs: capitalismo e esquizofrenia. v. 1. Rio de Janeiro: Editora 34; 1996.

21. Rolnik S. Cartografia sentimental. Porto Alegre: Editora da UFRGS; 2006.

22. Kastrup V. Cartografias literárias. Rev Dep Psicol UFF 2002; 14:75-94

23. Gonçalves RBM. Tecnologia e organização social das práticas de saúde: características tecnológicas de processo de trabalho na rede estadual e centros de saúde de São Paulo. São Paulo: Editora Hucitec/ Rio de Janeiro: ABRASCO; 1994.

24. Silva JA, Dalmaso ASW. O agente comunitário de saúde: o ser, o saber, o fazer. Rio de Janeiro: Editora Fiocruz; 2002.

25. Franco TB, Ferreira VSC, Andrade CS. Relatório de pesquisa "A Produção do Cuidado na Rede Básica". http://www.ba.uesc.br/atencaosaude (acessado em Jan/2008)

Recebido em 27/Mai/2008

Versão final reapresentada em 22/Set/2008 Aprovado em 14/Nov/2008 